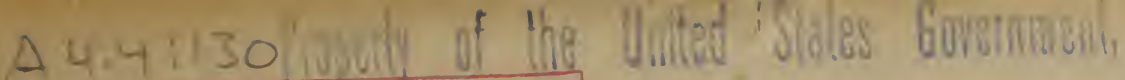

US. DEPOSITOAY U. S. DEPARTMENT OF AGRICULTURE,

\author{
BUREAU OF ANIMAL INDUSTRY.-CIRCULAR 130.
}

A, D. MelviN, Chief of Bureat.

\section{PARAFFINING BUTTER TUBS. ${ }^{a}$}

\author{
By L. A. Rogers, \\ Bacteriological Chemist, Dairy Division.
}

THE CAUSE OF MIOLDY BCTTER.

"Mold" is a term applied to a large group of very small plants. These plants are found growing on the damp surface of almost any substance which contains animal or vegetable matter. They are propagated by very small and very light spores, which are formed in enormous numbers and are so light that they are carried about by the slightest movement of the air. While they grow more rapidly at high temperatures, molds are not so sensitive to cold as many other plants, and they will grow even in refrigerators held at near the freezing point. In addition to food and proper temperature, a supply of air is absolutely necessary to their growth.

When molds grow on butter they not only give it an unsightly appearance, but bring about changes in its composition which seriously affect the flavor. Moldy butter is rery common, especially in the summer, and is a source of great annoyance and loss to butter dealers. Mold spores are so well distributed that it is impossible to secure tubs, boxes, or liners entirely free from contamination. If the rood is well seasoned and is stored in a dry place these spores will not germinate, but if the tubs or boxes are made from imperfectly seasoned lumber or become damp through improper storage, the spores will germinate and the contamination will be very much increased.

Moldy butter comes from tubs contaminated before they are nacked, and is not due to moldy refrigerators. Conditions which cause moldy refrigerators would favor the growth of mold on the inside of packed tubs, but the contamination for the most part must come before the tubs are filled.

a Application has been made for a patent on the apparatus described in this circular, in order that it may be used or manufactured by any person in the United States without the payment of royalty.

$$
4 \text { S521-0S }
$$

[Cir. 130] 
The trouble from moldy tubs may be decreased by using only well-seasoned tubs, storing them in a dry place before using and in a good refrigerator after filling. Since, however, it is not always possible to fulfill these conditions, some additional measures become necessary. These usually take the form of killing the molds on the tub by heating or by treating with an antiseptic. Tubs are frequently steamed before packing. but while this is of some benefit. it is not always effectual. Soaking in cold brine, hot brine, or brine with the addition of a small amount of formalin has been recommended.

A more recent method is to coat the inside of the tub with a thin layer of paraflin. 'This not only kills the molds on the tub, but also makes a surface on which molds can not grow. It has the added advantage of preventing the shrinking of the butter away from the tub. In unparaftined tubs the water is absorbed by the wood and an air space is formed between the butter and the tub in which molds on the tub or the liner will find farorable conditions for growth. In a paraftined tub this water is held and the molds are unable to obtain the air necessary to their growth.

The results of a few experiments made to determine the relative value of various methods of preventing moldy tubs are giren in Bulletin 89 of the Bureau of Animal Industry. Tubs were exposed in various ways to insure a thorough contamination. One tub in each lot was soaked over night in cold water, one was soaked in brine containing formalin, one was boiled in brine and allowed to stand in the hot brine over night, one was paraffined on the inside, and one was dipped in hot paraffin. After filling with butter they were held in the creamery refrigerator about the usual length of time and were shipped to a commission house, where they were examined when received.

It was found that all of the untreated tubs were badly molded. In those treated with brine and brine-formalin the mold was very materially checked, but the treatment could not be depended upon to prevent it entirely. The paraffined tubs were all free from mold. either on the tub or on the liner. In addition the paraffin made a neat, clean package, while the soaked tubs were more or less discolored and swollen.

\section{LOSS OF WEIGHT PREVENTED BI PARAFFINING.}

The advantage of paraflining is not alone in the prevention of mold growth. The well-recognized loss of weight in butter on standing is due to the absorption of water by the tub from the butter. This is almost entirely prevented by making the inside of the tub impervious 
to water by covering it with paraffin. The trouble and loss from molds falls largely on the butter dealer, but the loss of weight in shipment affects the creamery.

In one experiment 12 unparaffined tubs, containing $766 \frac{1}{4}$ pounds, lost $7 \frac{1}{ \pm}$ pounds in shipment. A similar lot of 12 paraffined tubs, containing 756 pounds of butter, lost in shipment only $1 \frac{1}{4}$ pounds.

When butter is held in storage in unparaffined tubs the loss from shrinkage is very appreciable. It should be remembered that a paraffined tub will weigh 2 or 3 pounds less than a tub soaked in the ordinary way. Therefore, if the tubs are not actually weighed, the advantage gained by paraffining is likely to be lost by the creamery. The cost of paraffining is very slight when compared with the loss from molding and shrinkage.

If properly applied 2 or 3 ounces of paraffin should be sufficient to coat a 60-pound tub. A good grade of paraffin can be bought for 8 or 9 cents a pound.

\section{MIOLDS IN PRINT BUTTER.}

It is more difficult to prevent mold on prints wrapped in paper and packed in boxes, because the air can not be excluded as it can in tubs. The boxes may be protected from mold by paraffining. Liners should be stored and protected from dust, and cartons should be so paraffined that they will not absorb water.

\section{APPLYING THE PARAFFIN.}

Paraffin should be hot enough to penetrate the wood slightly before it cools, otherwise it is likely to form a thick layer that will crack off. On the other hand, if it is too hot it will soak into the wood without filling the cracks. The proper temperature will depend somewhat on the method used, but is about $240^{\circ} \mathrm{F}$.

Paraffin may be applied by pouring a small amount of the hot wax into the tub and rotating the tub until the inner surface is covered. The more common way is to apply it with an ordinary flat paint brush, but this method is slow and it is difficult to secure a uniformly thin coat.

\section{MACHINES FOR APPLYING PARAFFIN.}

There are now on the market one or two machines for spraying the paraffin on the tubs. A machine designed by the writer has been in use in the experimental creamery of the Dairy Division for several months, and has given satisfaction. No special advantage is claimed for this machine over others, but it can be made by any good sheet-metal worker and is comparatively inexpensive. The illustration shows two views of the machine, the upper one being 


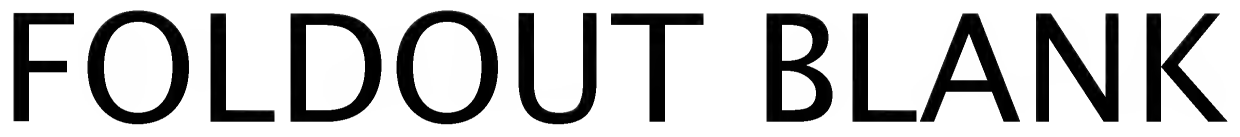




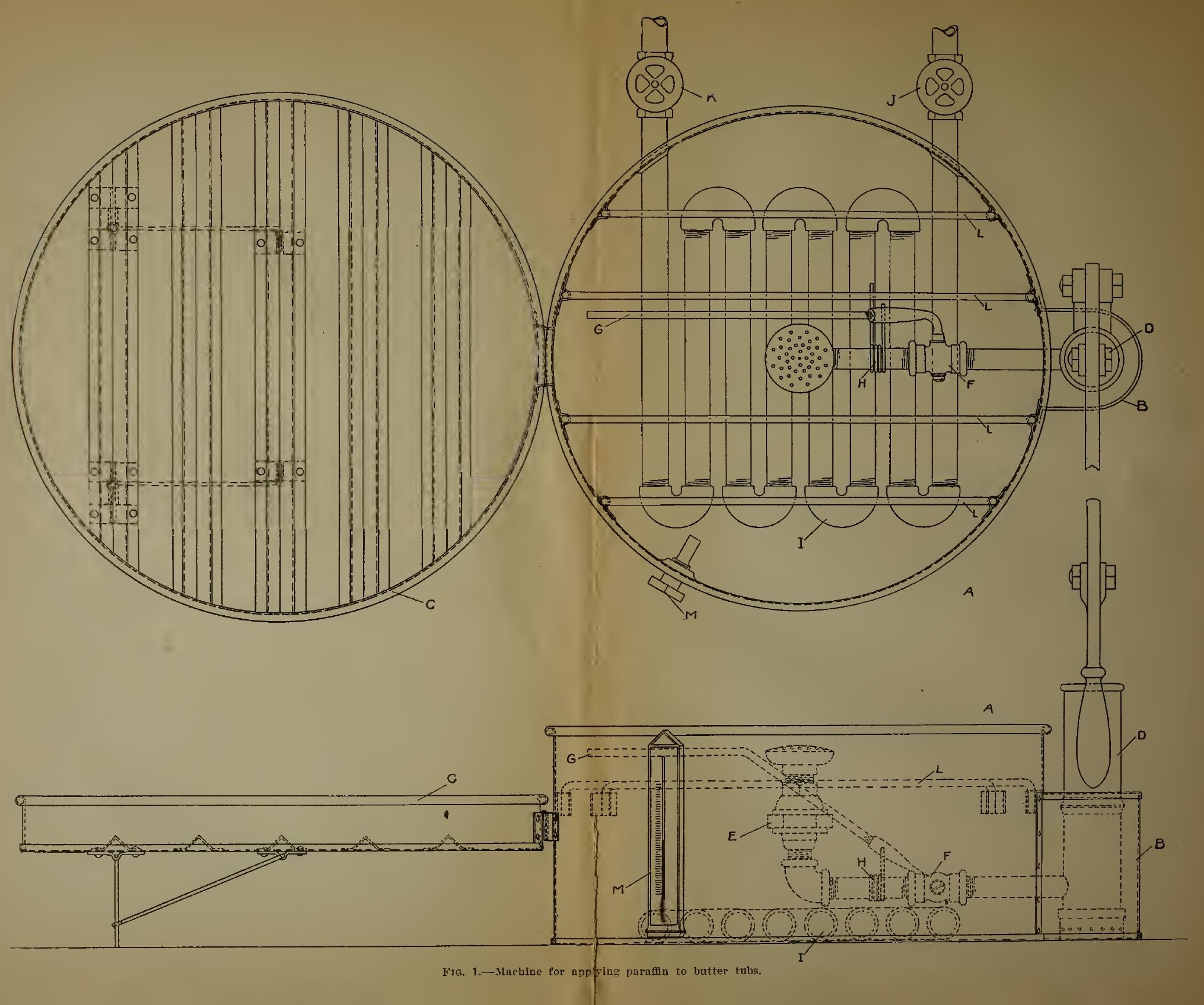



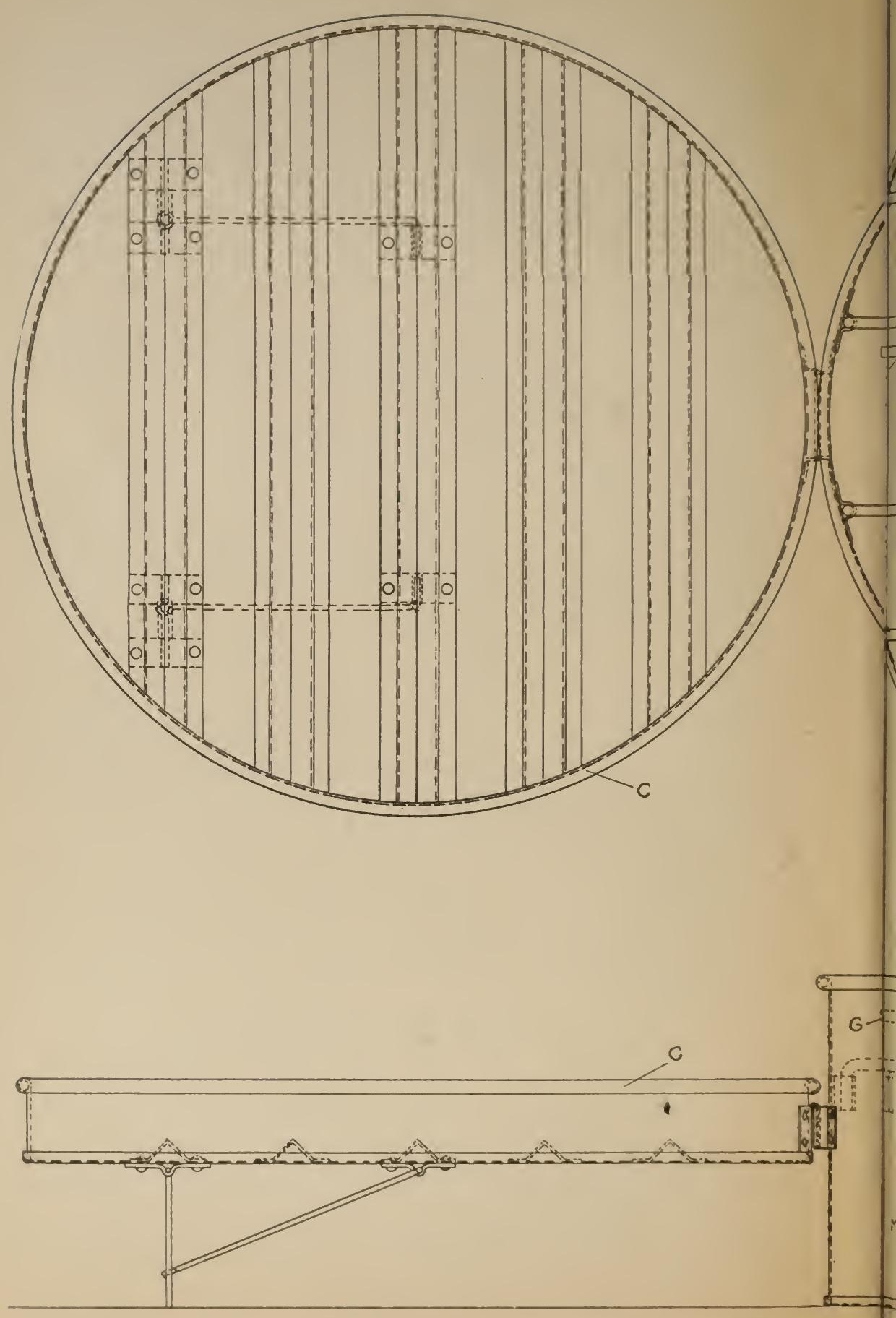

Fig. 1.-Macbine for apt 
a view looking down into it, with the inverted cover in position alongside: the lower one is an elevation showing the interior arrangrement. The machine consists of a galvanized-iron tank $A$ with a smaller tank Bs. the small tank having an unobstructed opening into the large tank. In tank $B$ is securely fastened an ordinary plumb(re's force pump I). The inlet is through perforations at the base of the pump and the discharge through the check valve at $E$. On the bottom of the tank $d$ is a steam heating coil $I$ with a valve at $J$. where it is connected with the high-pressure steam system, and at the outlet $h$. The four cross rods LL support the inverted tub. It $F$ is a cut-off ralve. The lever handle is extended by a rod $G$. A spring at $I I$ is so adjusted that the valve is closed when the machine is not in use. To operate the tank it should be filled with paraffin until the heating pipes are well covered; the ralve $J$ is opened, also the outlet valve $\bar{l}$, sufficiently to allow the water of condensation to eseape. I high temperature is obtained in this way. and the paraffin may be heated in a short time to the desired temperature. which is regulated by opening or closing the valve $J$. The temperature should be not less than $240^{\circ} \mathrm{F}$., and is conveniently determined by an angle thermometer at $M$.

When the paraffin is hot a tub is set bottom up on the rods $L L$. The weight of the tub presses down the lever opening the valve $F$. and a few strokes of the pump spray the paraffin over the insicle of the tub. This is then set to drain on the inverted cover $C$. The paraffin which drains into the cover can be put back into the rat. If the tub is not evenly coated the paraffin should be heated to a higher temperature or the tub steamed before paraffining.

The valve $F$ may be considered unnecessary, but when one takes into account the possibility that children or other curiously inclined people may spray hot paraffin into their faces it is well worth the additional expense. The check valves should be all metal, and an asbestos packing should be used on the plunger of the pump, as the hot paraffin soon destroys leather.

The diameter of the tank A should be slightly greater than the top of a 60 -pound tub. The other dimensions will depend largely on the pump used.

Ipproved:

JAMES WILSON,

Secretary of Agriculture.

Wasmington, D. C., Jume 15. 1908. [Cir. 130] 

UNIVERSITY OF FLORIDA 